\title{
Short communication: Relationship between methods for measurement of serum electrolytes and the relationship between ionized and total calcium and neutrophil oxidative burst activity in early postpartum dairy cows
}

\author{
B. M. Leno, ${ }^{*}$ E. M. Martens, ${ }^{*}$ M. J. B. Felippe,† K. P. Zanzalari,‡ J. C. Lawrence,§ and T. R. Overton*1 \\ *Department of Animal Science, and \\ †Department of Clinical Sciences, College of Veterinary Medicine, Cornell University, Ithaca, NY 14853 \\ †Phibro Animal Health Corp., Quincy, IL 62305 \\ §IDEXX Laboratories Inc., Westbrook, ME 04092
}

\section{ABSTRACT}

The objectives of this study were to (1) compare a test for serum measurement of total $\mathrm{Ca}(\mathrm{tCa}), \mathrm{Mg}$, and $\mathrm{P}$ (VetTest Chemistry Analyzer, IDEXX Laboratories Inc., Westbrook, ME) to reference methods (spectrophotometric assays on a Beckman Coulter 640e automated clinical chemistry analyzer; Beckman Coulter, Brea, CA), (2) determine the relationship between ionized $\mathrm{Ca}(\mathrm{iCa})$ and reference method tCa in the immediate postpartum period, and (3) assess the relative value of these blood $\mathrm{Ca}$ indices as predictors of neutrophil oxidative burst activity. Samples were collected from multiparous Holstein cows $(\mathrm{n}=33)$ over the first $5 \mathrm{~d}$ in milk. A total of 183 samples for objective 1 and 181 samples for objective 2 were available. Neutrophil oxidative burst activity was assessed once between 2 and $5 \mathrm{~d}$ in milk $(\mathrm{n}=29)$. Linear regression demonstrated strong relationships between serum tCa, Mg, and $\mathrm{P}$ concentrations measured by the VetTest compared with the reference method. Bland Altman analysis indicated that the VetTest values were higher than the reference method by $0.22 \mathrm{mmol} / \mathrm{L}$ for tCa, $0.12 \mathrm{mmol} / \mathrm{L}$ for $\mathrm{Mg}$, and $0.16 \mathrm{mmol} / \mathrm{L}$ for $\mathrm{P}$. Compared with hypocalcemia categorized at $\leq 2.0$ or $\leq 2.125 \mathrm{mmol} / \mathrm{L}$ with the reference method tCa, thresholds for the VetTest measured tCa of $\leq 2.23 \mathrm{mmol} / \mathrm{L}$ (sensitivity $=87 \%$, specificity $=89 \%$ ) or $\leq 2.30 \mathrm{mmol} / \mathrm{L}$ (sensitivity $=86 \%$, specificity $=96 \%$ ) could be used. The relationship between whole-blood iCa and reference method serum tCa differed by sampling time point after calving. Compared with identification of hypocalcemia with serum tCa measurements from the reference method (thresholds of $\leq 2.0$ and $2.125 \mathrm{mmol} / \mathrm{L}$ ), a whole-blood iCa threshold

\footnotetext{
Received April 1, 2017.

Accepted July 18, 2017.

${ }^{1}$ Corresponding author: tro2@cornell.edu
}

of $\leq 1.17 \mathrm{mmol} / \mathrm{L}$ resulted in the highest combined sensitivities (94 and 82\%) and specificities (80 and 94\%) at either threshold. Ionized $\mathrm{Ca}$ measurements were more consistently related to outcomes of neutrophil oxidative burst activity measured in vitro. The VetTest measurements of serum tCa reliably identified hypocalcemia when thresholds were adjusted to account for the bias of the test. The variation in the relationship between $\mathrm{iCa}$ and reference method tCa in the days following parturition suggest that these measures cannot be used interchangeably as indicators of $\mathrm{Ca}$ status. The more consistent associations between iCa and in vitro measures of neutrophil function, compared with tCa, indicated that this may be a more sensitive predictor of functional outcomes associated with postpartum $\mathrm{Ca}$ status.

Key words: calcium, neutrophils

\section{Short Communication}

Hypocalcemia is a disorder resulting from the rapid increase in demand for $\mathrm{Ca}$ that occurs as dairy cows transition from late gestation to lactation (Ramberg et al., 1970). Although blood Ca concentrations are regulated homeostatically, many cows experience a lag in adaptation to this increased demand, resulting in decreased blood Ca concentrations that can take several days to return to normal (Ramos-Nieves et al., 2009). Recent research has demonstrated that approximately $25 \%$ of primiparous cows and $50 \%$ or more of multiparous cows are affected by hypocalcemia (Reinhardt et al., 2011; Caixeta et al., 2015). The consequences of the disorder span from increased disease and earlylactation culling to lost milk production and decreased reproductive performance (Chapinal et al., 2011, 2012; Martinez et al., 2012; Roberts et al., 2012).

As a result of the associations between hypocalcemia and productive and health outcomes of economic importance, interest in the ability to monitor the Ca 
status of cows at the herd and individual animal level has increased. In the majority of cases, cows do not display clinical signs of the disorder and hypocalcemia must be identified through the measurement of blood Ca (Reinhardt et al., 2011; Caixeta et al., 2015). Calcium circulates in blood in 3 forms; ionized $\mathrm{Ca}$ (iCa) and $\mathrm{Ca}$ bound to either proteins or anions (Rosol et al., 1995). The summation of these 3 forms, referred to as total $\mathrm{Ca}(\mathbf{t C a})$, is most often measured to assess the Ca status of a cow due to ease of sample handling, storage, and analysis. Recent epidemiological studies have established blood $\mathrm{Ca}$ thresholds for identification of hypocalcemia based on the tCa concentration after parturition (Chapinal et al., 2011; Martinez et al., 2012). On-farm application of blood tCa measurement has been implemented minimally because of the lack of studies comparing tests that are easy to use and costeffective compared with methods typically employed in veterinary diagnostic laboratories.

It has been hypothesized that blood iCa concentration more accurately reflects the functional Ca status of the cow because this is the form of Ca readily available to cells to perform intracellular signaling necessary for such functions as contraction of muscles and activation of immune cells (Kimura et al., 2006); in addition, tCa is affected by blood protein levels (Rosol et al., 1995; Seifi et al., 2005). Ionized Ca is challenging to accurately measure because exposure of samples to air as well as the use of anticoagulants can change the proportion of Ca that is ionized in the sample (Boink et al., 1991). Although research has established thresholds for identification of hypocalcemia based on tCa, some work has extrapolated this to categorize Ca status using $\mathrm{iCa}$ measurements based on the assumption that iCa constitutes approximately $50 \%$ of tCa, which has been determined in clinically normal cows (Lincoln and Lane, 1990). Some evidence suggests that the relationship between tCa and iCa may be different around the time of parturition, with a higher proportion of $\mathrm{Ca}$ in the ionized form (Ballantine and Herbein, 1991; Joyce et al., 1997). If iCa more accurately reflects the functional Ca status of the cow, and the relationship to tCa is not consistent with previous assumptions in this period, this would suggest that thresholds using iCa for identification of hypocalcemia should be established independently to account for these dynamics immediately after calving.

The first objective of our study was to compare serum electrolytes measured by a commercially available test with potential on-farm application to measurements using reference methods at a veterinary diagnostic laboratory. The second objective of our study was to assess the relationship between iCa and reference method tCa measured in the immediate postpartum period. Our third objective was to assess the relative value of $\mathrm{iCa}$ and tCa for explaining variation in neutrophil oxidative burst activity. Neutrophils are a major cell activated in the innate immune response and are an important component of expelling the placenta after parturition (Kimura et al., 2002). Further, uterine disease risk has been associated with compromised neutrophil function in the transition period (Hammon et al., 2006). Oxidative burst activity of neutrophils is an index of killing capacity, and reductions in this function have been associated with induced subclinical hypocalcemia (Martinez et al., 2014), as well as spontaneous subclinical hypocalcemia occurring after parturition (Martinez et al., 2012).

Cows enrolled in this observational study represented a convenience sample of Holstein cows calving from June to July of $2013(\mathrm{n}=17)$ and January to February of $2014(\mathrm{n}=16)$ at the Cornell University dairy research farms (Harford, NY). Eligibility criteria for enrollment included parity (entering second or greater lactation), apparently healthy before parturition, and absence of Staphylococcus aureus mastitis in past lactations. The population included 15 cows entering their second lactation and 18 cows entering their third or greater lactation. All animal procedures were approved by the Cornell University Institutional Animal Care and Use Committee before the start of the study.

Samples of rations fed during the prepartum period were collected weekly, and a composite sample from each enrollment period was analyzed at a commercial laboratory (Cumberland Valley Analytical Services, Hagerstown, MD). Prepartum ration DCAD [mEq/100 $\mathrm{g}$ of $\left.\mathrm{DM}=\left(\mathrm{Na}^{+}+\mathrm{K}^{+}\right)-\left(\mathrm{Cl}^{-}+\mathrm{S}^{2-}\right)\right]$ for cows calving between June and July of 2013 was $6.4 \mathrm{mEq} / 100$ $\mathrm{g}$ of DM, and for cows calving between January and February of 2014 was $-6.1 \mathrm{mEq} / 100 \mathrm{~g}$ of DM. This reflects some degree of additional anion inclusion in these rations for prevention of hypocalcemia and, although they represent different degrees of implementation of a preventative approach, this range of ration DCAD would be considered representative of preventative strategies implemented in the field.

Blood samples were collected from all cows twice in the $24 \mathrm{~h}$ after calving (the next 2 samplings after calving with the morning sampling, occurring between 0600 and $0730 \mathrm{~h}$, and the evening sampling, occurring between $1630 \mathrm{~h}$ and $1700 \mathrm{~h}$ ), referred to as 0.3 and 0.6 DIM in the results, and once daily for the following 4 $\mathrm{d}$ at the morning sampling. Sampling was discontinued if cows were identified as clinically hypocalcemic by farm personnel and required treatment with intravenous $\mathrm{Ca}(\mathrm{n}=3)$. Samples collected before treatment remained in the data set. A total of 183 samples for comparison of serum $\mathrm{tCa}, \mathrm{Mg}$, and $\mathrm{P}$ methods were 
available, and 181 samples for the comparison of iCa and reference method tCa, due to sample-clotting issues in 2 samples before measurement of whole-blood iCa. Samples were collected from the coccygeal vessels using 20-gauge needles and 6-mL syringes (Covidien, Minneapolis, MN) containing no anticoagulant. Whole blood was dispensed into cartridges (CHEM8+, Abbott Point of Care Inc., Princeton, NJ) according to manufacturer instructions (https://www.pointofcare.abbott/ us/en/offerings/support/technical-documentation/

istat-system-manuals) for analysis of $\mathrm{iCa}$ within $3 \mathrm{~min}$ of sample collection using an iSTAT Portable Clinical Analyzer (iSTAT; Abbott Point of Care Inc.), which uses ion selective electrode potentiometry. The whole blood was then dispensed into $16 \times 100 \mathrm{~mm}$ glass tubes, capped, allowed to clot at room temperature and centrifuged at $2,000 \times g$ for $20 \mathrm{~min}$ at $25^{\circ} \mathrm{C}$. Serum was harvested and a portion of the serum was analyzed for tCa, $\mathrm{Mg}$, and $\mathrm{P}$ concentration using the VetTest Chemistry Analyzer (VetTest; IDEXX Laboratories Inc., Westbrook, ME). Quality-control tests were run and samples were analyzed according to manufacturer instructions. The remaining serum was aliquoted into $1.7-\mathrm{mL}$ microfuge tubes and stored at $-20^{\circ} \mathrm{C}$. Serum was shipped overnight on dry ice to the Michigan State Diagnostic Center for Population and Animal Health (Lansing, MI) for determination of total $\mathrm{Ca}, \mathrm{Mg}$, and $\mathrm{P}$ using an automated clinical chemistry analyzer (Beckman Coulter 640e, Beckman Coulter Inc., Brea, CA) with reagents provided by the company. The analysis conducted by the autoanalyzer was considered the reference method. For total $\mathrm{Ca}$, the reaction between $\mathrm{Ca}$ in the sample and arsenazo III results in a purple complex, the absorbance is measured bichromatically at $660 / 800 \mathrm{~nm}$, and the increase in absorbance is directly proportional to the total $\mathrm{Ca}$ in the sample. For $\mathrm{Mg}$, the reaction between $\mathrm{Mg}$ in the sample and xylidyl blue results in a purple complex, interference by $\mathrm{Ca}$ is controlled by inclusion of glycoletherdiamine$N, N, N, N$-tetraacetic acid, the absorbance is measured bichromatically at $520 / 800 \mathrm{~nm}$, and the increase in absorbance is proportional to the $\mathrm{Mg}$ concentration. Phosphorus is determined by the reaction between inorganic phosphate in the sample and molybdate which form a heteropolyacid complex, the absorbance is measured bichromatically at $340 / 380 \mathrm{~nm}$, and the increase in absorbance due to the formation of this complex is proportional to the inorganic phosphorus in the sample. According to the manufacturers, the results of these analyses are not significantly affected by hemolysis up to $500 \mathrm{mg} / \mathrm{dL}$ for Ca, $150 \mathrm{mg} / \mathrm{dL}$ for $\mathrm{Mg}$ and $350 \mathrm{mg} /$ $\mathrm{dL}$ for $\mathrm{P}$. The laboratory generated intra-assay coefficients of variation were $0.8 \%$ for $\mathrm{Ca}, 2.7 \%$ for $\mathrm{P}$, and $4.0 \%$ for $\mathrm{Mg}(\mathrm{n}=20)$. According to the manufacturer, total coefficients of variation (measured by repeated analysis over several days) at low and high concentrations were 1.3 and $0.8 \%$ for $\mathrm{Ca}, 2.1$ and $0.9 \%$ for $\mathrm{P}$, and 1.4 and $2.1 \%$ for $\mathrm{Mg}$, respectively. A visual hemolysis assessment was conducted at the diagnostic laboratory, and no samples had severe hemolysis. The assays for the VetTest machine were based on the reaction with arsenazo III for $\mathrm{Ca}$, formazan dye for $\mathrm{Mg}$, and ammonium molybdate, and p-methylaminophenol sulfate for $\mathrm{P}$. The VetTest machine has internal filters that approximate the wavelengths for reading reactions at $680 \mathrm{~nm}$ for Ca (using an offset based on manufacturer calibration), $650 \mathrm{~nm}$ for $\mathrm{Mg}$, and $650 \mathrm{~nm}$ for P. The manufacturers indicated no significant effects of hemolysis for the VetTest; however, the effect of hemolysis on these assays was not assessed in the current study.

An additional blood sample was collected from all cows that did not receive intravenous $\mathrm{Ca}$ treatment (n $=30$ ) at 1 sampling between 2 and 5 DIM for flow cytometric determination of neutrophil oxidative burst activity using a commercial kit (Phagoburst, Glycotope GmbH, Berlin, Germany), as described by Yasui et al. (2016). Data from 1 cow was excluded because of laboratory error. The final neutrophil function data set included 16 and 13 cows from the first and second enrollment periods, respectively, with 15 second-lactation cows and 14 cows in their third and greater lactation. Samples were collected using a 20-gauge vacutainer needle (Becton Dickinson, Franklin Lakes, NJ) and $10-\mathrm{mL}$ vacutainer tube containing sodium heparin (158 USP, Becton Dickinson), placed on ice, transported to the laboratory, and analyzed within $2 \mathrm{~h}$. Flow cytometric analysis of oxidative burst activity was conducted using a BD FACSCalibur flow cytometer with a 488$\mu \mathrm{m}$ argon laser (Becton Dickinson). Data analysis was conducted using Cell Quest Analysis software (Becton Dickinson). Data were collected from a minimum of 10,000 leukocytes per assay tube. Scatterplots of forward light scatter and side light scatter were used to separate cell populations based on cell size and granularity to gate the subpopulation of neutrophils and to remove the population of cells with spontaneous fluorescence that was apparent in negative control tubes. Data from the tube stimulated with preopsonized, nonlabeled Escherichia coli, and the tube stimulated with phorbol 12-myristate 13-acetate (PMA; high stimulus) were compared with the negative control tube (wash solution added in place of stimulant). To control for day-to-day variation, histogram plots of fluorescence activity for gated neutrophils in negative control tubes were used to set margins for each cow so that less than $5 \%$ of the neutrophil population was positive. These histogram margins were then applied to the data acquired from stimulated tubes for that cow to determine the 
number of neutrophils with fluorescence activity higher than the negative control tube (positive percent) and the geometric mean fluorescence intensity (GMFI) of those neutrophils, which represents the mean oxidative burst activity of activated neutrophils.

Analysis of the association between methods for blood electrolyte measurement was conducted using the MIXED procedure of SAS (version 9.4, SAS Institute Inc., Cary, NC). To determine the association between the test method (VetTest) and the reference method for total serum electrolytes, linear regression was conducted using the reference measurement as the fixed effect, with cow as the subject of repeated measures to account for the covariance of measurements taken from the same cow. Four covariance structures were tested (compound symmetry, heterogeneous compound symmetry, antedependence, and unstructured), with selection based on the lowest Akaike's information criterion. The estimate for the slope of the regression lines and the associated $P$-values are presented. To determine if the relationship between $\mathrm{iCa}$ and the reference method tCa varied by sampling time point, multivariate regression was conducted with whole-blood iCa as the outcome, and the reference method serum tCa, sampling time point, and the interaction of serum tCa and sampling time point included as the fixed effects, accounting for cow as the subject of repeated measures with covariance structure selection as described above. Because the interaction between sampling time point and reference method tCa was significant $(P<0.0001)$, a stratified analysis by sampling time point was conducted. The regression slopes and associated $P$-values of the simple linear regression analysis at each time point are presented. Agreement between the VetTest measurements of total $\mathrm{Ca}, \mathrm{Mg}$, and $\mathrm{P}$ with the reference method were assessed using Bland Altman plots in the software MedCalc (MedCalc Software, Ostend, Belgium), and the mean differences of the methods (reference method value minus the VetTest value) across the range of values are presented. Receiver operator characteristic (ROC) analysis was used to determine the thresholds for serum tCa measured by the VetTest, and whole-blood iCa that resulted in the highest combined sensitivity and specificity for identifying hypocalcemia according to the reference method categorization at 2 different serum tCa thresholds $(\leq 2.0$ and $\leq 2.125$ $\mathrm{mmol} / \mathrm{L})$. Significance was declared at $P \leq 0.05$.

The relative value of whole-blood iCa versus serum tCa measured by the reference method as predictors of neutrophil oxidative burst activity was tested using multivariate models in PROC MIXED. Outcomes included positive percent and GMFI for E. coli- and PMA-stimulated neutrophils. A data transformation was conducted for PMA-stimulated positive percent
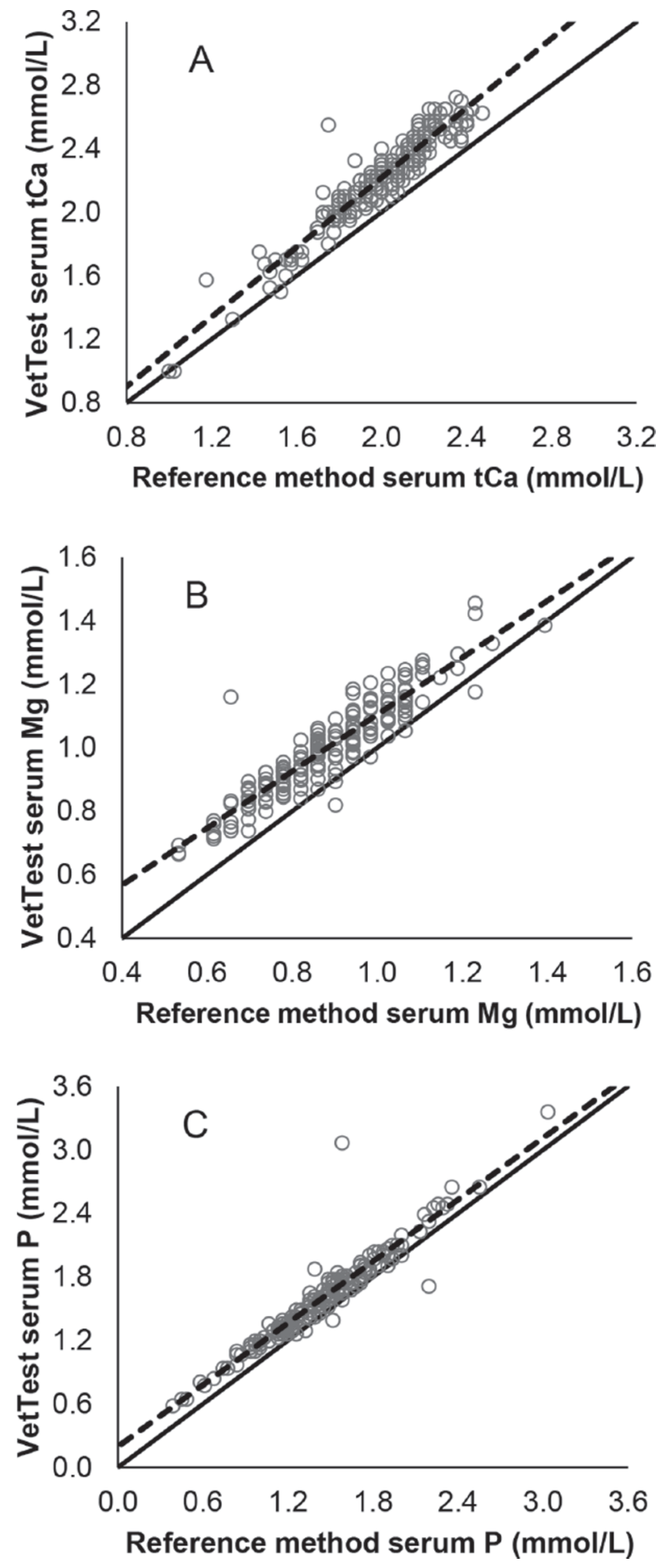

Figure 1. Linear regression between serum electrolyte concentrations measured with a test method (VetTest Chemistry Analyzer, IDEXX Laboratories Inc., Westbrook, ME) and a reference method [Beckman Coulter 640e automated chemistry analyzer with Beckman Coulter reagents $($ Brea, CA)]. Samples $(\mathrm{n}=183)$ were collected from 33 multiparous Holstein cows over the $5 \mathrm{~d}$ following parturition. Dashed line represents linear regression line and solid line represents the line of unity. Panel $\mathrm{A}=$ serum total $\mathrm{Ca}(\mathrm{tCa} ; \mathrm{mmol} / \mathrm{L})$, slope $=$ $1.08 \pm 0.03, P<0.0001 ; \mathrm{B}=$ serum $\mathrm{Mg}(\mathrm{mmol} / \mathrm{L})$, slope $=0.89 \pm$ $0.02, P<0.0001 ; \mathrm{C}=\operatorname{serum} \mathrm{P}(\mathrm{mmol} / \mathrm{L})$, slope $=0.99 \pm 0.01, P<$ 0.0001 . 

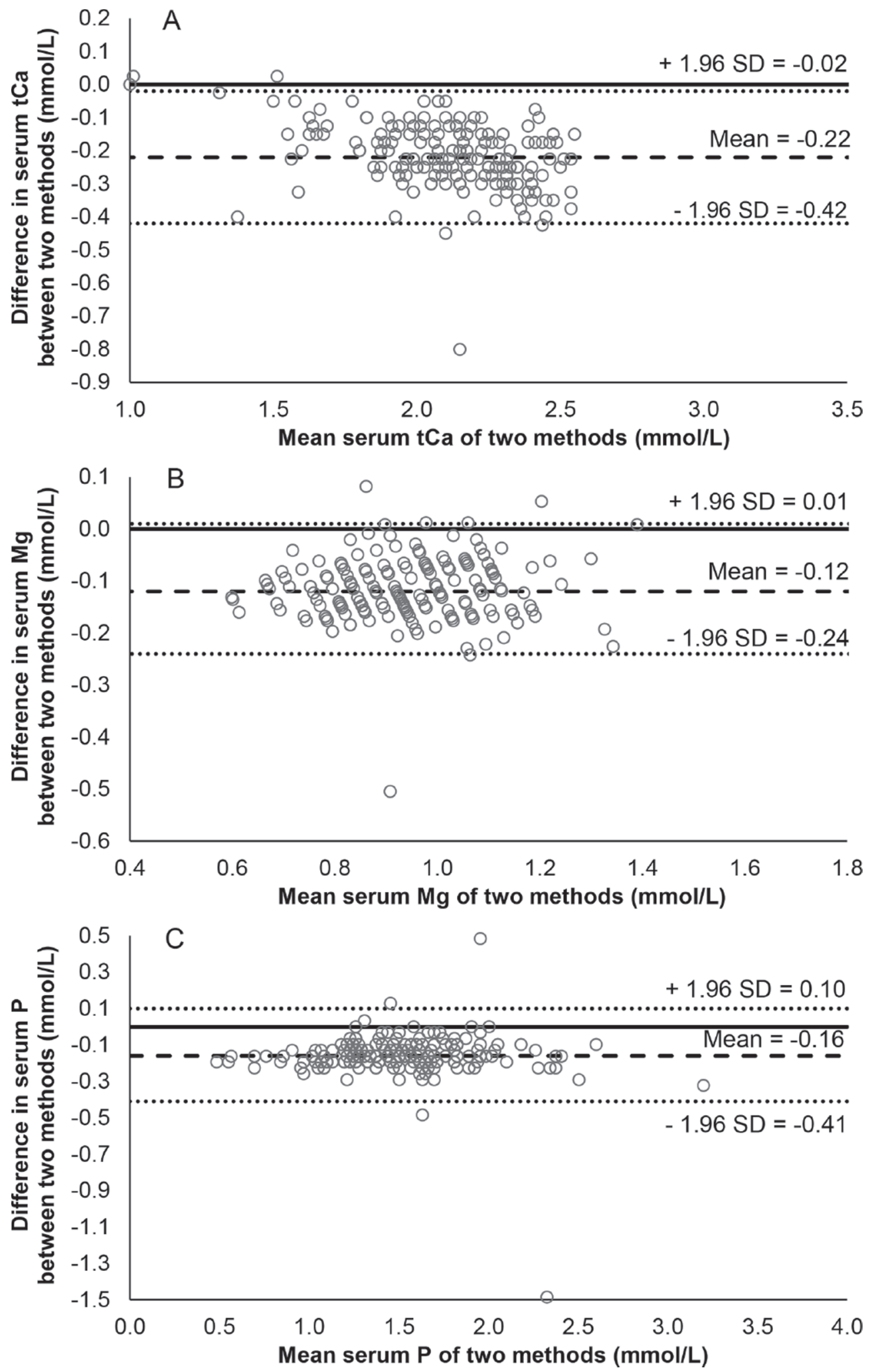

Figure 2. Bland Altman plots comparing the difference between a reference method [Beckman Coulter 640e automated chemistry analyzer with Beckman Coulter reagents (Brea, CA)] and a test method (VetTest Chemistry Analyzer, IDEXX Laboratories Inc., Westbrook, ME) to the mean of the 2 methods for measurement of serum total Ca (tCa; A), serum $\mathrm{Mg}(\mathrm{B})$, and serum $\mathrm{P}(\mathrm{C})$. y-axis = reference method value - VetTest value. Samples $(\mathrm{n}=183)$ were collected from 33 multiparous Holstein cows over the $5 \mathrm{~d}$ following parturition. The solid line represents a mean difference of zero, the dashed line represents the observed mean difference, and the dotted lines represent the $95 \%$ CI of the mean difference. 
before analysis to account for a left-skewed distribution [transformed value $=\ln (101-$ positive percent $)$. For each outcome, 4 separate models were analyzed that included 1 of the following indexes of Ca status: minimum whole-blood $\mathrm{iCa}$ or reference method serum tCa (measured on or before the day of neutrophil assessment) and the whole-blood iCa or reference method serum tCa measured on the day of neutrophil assessment. Confounders that were included in all models included parity (second vs. third lactation and greater) and season (summer 2013 vs. winter 2014). The slope estimates from the multivariable models for the effect of Ca status indexes with $P \leq 0.05$ are reported and discussed.

The linear regression demonstrated strong relationships between blood electrolytes measured by the VetTest compared with the reference method for serum tCa (slope $=1.08 \pm 0.02, P<0.0001$ ), serum $\mathrm{Mg}$ (slope $=0.89 \pm 0.02, P<0.0001$ ), and serum $\mathrm{P}$ (slope $=0.99 \pm 0.01, P<0.0001)$, and these relationships are displayed in Figure 1. The Bland Altman plots of the comparison between the 2 methods are presented in Figure 2. The Bland Altman plots are necessary to determine the mean bias when comparing a test method to a reference method. The negative mean bias for the reference method value minus the VetTest value indicated that the VetTest read higher by $0.22 \mathrm{mmol} / \mathrm{L}$ (95\% CI $=0.02$ to 0.42$)$ for Ca, $0.12 \mathrm{mmol} / \mathrm{L}(95 \% \mathrm{CI}$ $=-0.01$ to 0.24$)$ for $\mathrm{Mg}$, and $0.16 \mathrm{mmol} / \mathrm{L}(95 \% \mathrm{CI}$ $=-0.10$ to 0.41$)$ for P. Results of the ROC analysis for identification of hypocalcemia using the VetTest compared with the reference method are presented in Table 1. Compared with the reference method using a serum tCa threshold of $\leq 2.0 \mathrm{mmol} / \mathrm{L}$, a threshold of $\leq 2.23 \mathrm{mmol} / \mathrm{L}$ for serum tCa measured by the VetTest resulted in a sensitivity and specificity of 87 and $89 \%$, respectively. The VetTest performed similarly well but with higher specificity at a higher reference method threshold of $\leq 2.125 \mathrm{mmol} / \mathrm{L}$, at which a threshold for serum tCa measured by the VetTest of $\leq 2.30 \mathrm{mmol} / \mathrm{L}$ performed with a sensitivity and specificity of 86 and $96 \%$, respectively.

The linear regression between whole-blood iCa and reference method serum tCa measured at each of the sampling time points is presented in Figure 3. A linear relationship between these 2 blood Ca fractions was observed at each time point $(P \leq 0.0004)$, and the equations for the regression lines are presented in Figure 3 . The results of the ROC analysis for hypocalcemia identification using whole-blood iCa compared with the reference method serum tCa measurement are presented in Table 1. Compared with the reference method categorization of Ca status at either threshold $(\leq 2.0$ or $\leq 2.125 \mathrm{mmol} / \mathrm{L}$ ), a whole-blood iCa threshold of $\leq 1.17$ $\mathrm{mmol} / \mathrm{L}$ resulted in the highest combined sensitivity and specificity. Compared with the lower reference method threshold, the sensitivity and specificity was 94 and $84 \%$, respectively; at the higher reference method threshold, the sensitivity and specificity were 82 and $94 \%$, respectively. If a threshold of $\leq 1.0 \mathrm{mmol} / \mathrm{L}$ for iCa was compared with a reference method serum tCa threshold of $\leq 2.0 \mathrm{mmol} / \mathrm{L}$, the sensitivity and specificity for identifying hypocalcemia were 39 and $98 \%$, respectively, resulting in a high proportion of falsenegative tests. This threshold has been used in previous research for hypocalcemia identification (Chamberlin et al., 2013), likely based on the relationship between tCa and iCa demonstrated in healthy cows (Lincoln and Lane, 1990). Our data suggest that assumed relationships between iCa and tCa do not reliably identify the same population of cows.

The effects of Ca status indexes on measures of neutrophil oxidative burst activity are presented in Table 2. Neither minimum iCa nor minimum reference method tCa were associated with any of the measures of neutrophil function $(P \geq 0.21)$; therefore, only asso-

Table 1. Receiver operator characteristic analysis of 2 different methods for measuring blood Ca status compared with hypocalcemia identification at 2 thresholds by a reference method ${ }^{1}$ for serum total Ca concentration determination

\begin{tabular}{|c|c|c|c|c|c|}
\hline Method $^{2}$ & $\begin{array}{l}\text { Threshold }^{3} \\
(\mathrm{mmol} / \mathrm{L})\end{array}$ & $\begin{array}{l}\text { Area under the } \\
\text { curve }(95 \% \mathrm{CI})\end{array}$ & $P$-value & $\begin{array}{l}\text { Sensitivity } \\
(95 \% \text { CI })\end{array}$ & $\begin{array}{l}\text { Specificity } \\
(95 \% \text { CI })\end{array}$ \\
\hline \multicolumn{6}{|l|}{ VetTest serum total $\mathrm{Ca}$} \\
\hline \multicolumn{6}{|l|}{ iSTAT whole blood ionized $\mathrm{Ca}^{-}$} \\
\hline Reference method threshold $\leq 2.0 \mathrm{mmol} / \mathrm{L}$ & $\leq 1.17$ & $0.93(0.88-0.96)$ & $<0.0001$ & $94.3(87.1-98.1)$ & $80.2(70.8-87.6)$ \\
\hline Reference method threshold $\leq 2.125 \mathrm{mmol} / \mathrm{L}$ & $\leq 1.17$ & $0.93(0.88-0.96)$ & $<0.0001$ & $82.2(74.1-88.6)$ & $93.9(85.0-98.3)$ \\
\hline
\end{tabular}


ciations for iCa and reference method tCa measured on the day of neutrophil assessment are presented. Neither Ca status index measured on the day of neutrophil assessment was associated with PMA-stimulated neutrophil positive percent $(P \geq 0.36)$. Both iCa $(P=0.001)$ and reference method tCa $(P=0.02)$ measured on the day of neutrophil assessment were positively associ- ated with PMA-stimulated neutrophil GMFI. Ionized Ca measured on the day of neutrophil assessment was positively associated with $E$. coli-stimulated neutrophil positive percent $(P=0.004)$ and GMFI $(P=0.02)$, but we found no association of reference method tCa with E. coli-stimulated positive percent $(P=0.14)$ or GMFI $(P=0.48)$.
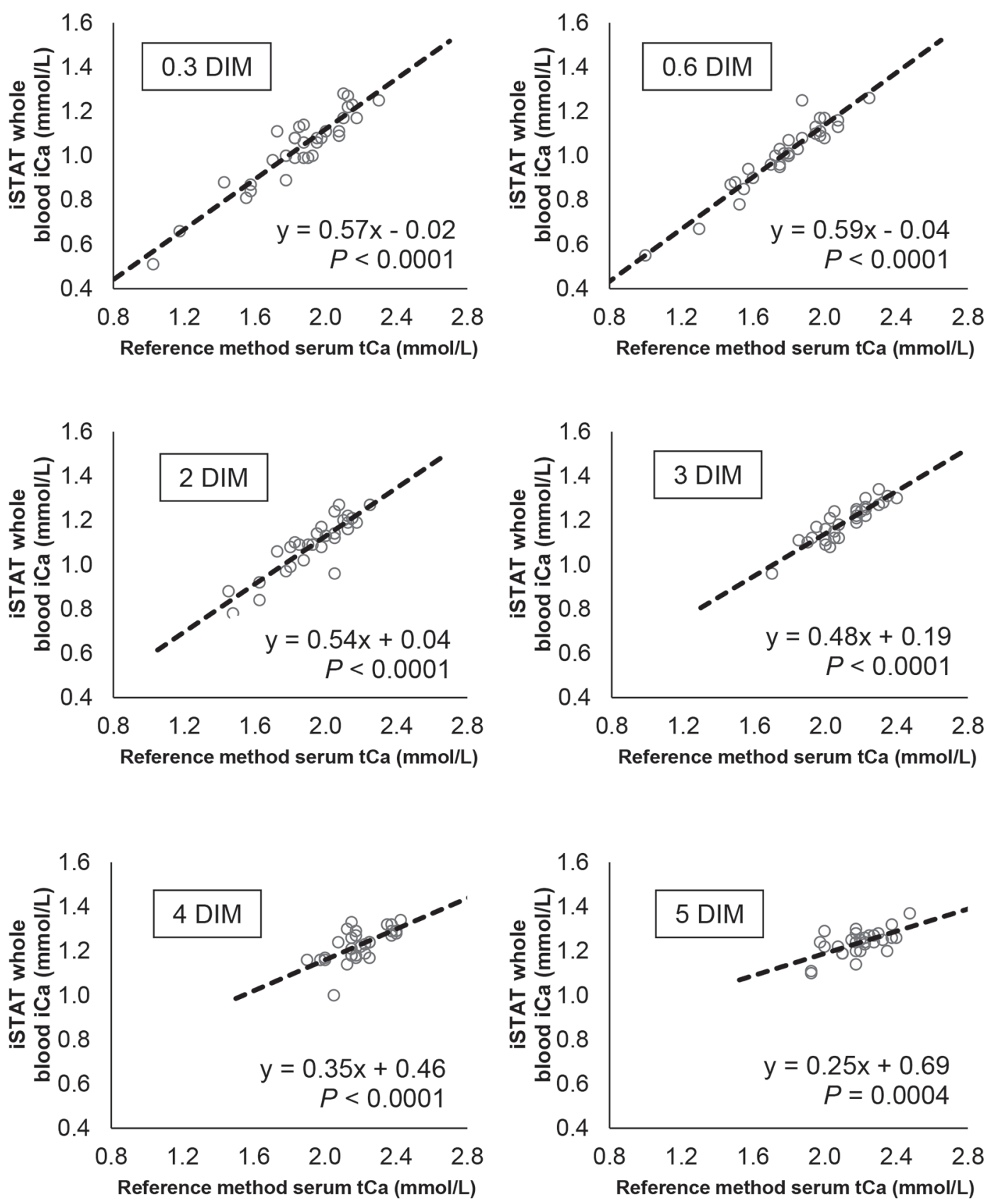

Figure 3. Linear regression between ionized $\mathrm{Ca}$ (iCa) measured in whole blood (iSTAT Portable Clinical Analyzer, Abbott Point of Care Inc., Princeton, NJ) and total Ca (tCa) measured in serum by a reference method [Beckman Coulter 640e automated chemistry analyzer with Beckman Coulter reagents (Brea, CA)] by sampling time point after parturition. Each plot represents 1 sampling time point as indicated. Samples $(\mathrm{n}=181)$ were collected from 33 multiparous Holstein cows over the $5 \mathrm{~d}$ following parturition. The dashed line represents the linear regression line, and the equations of the regression lines are displayed with the $P$-value for the simple linear regression. 
Table 2. Association between indices of $\mathrm{Ca}$ status and indices of neutrophil oxidative burst activity assessed by in vitro stimulation of neutrophils in whole blood with Escherichia coli or phorbol 12-myristate 13-acetate (PMA) ${ }^{1}$

\begin{tabular}{|c|c|c|c|c|c|}
\hline \multirow{2}{*}{ Outcome } & \multirow{2}{*}{ Mean $\pm \mathrm{SD}$} & \multicolumn{4}{|c|}{ Calcium status index } \\
\hline & & \multicolumn{2}{|c|}{ Assay day $\mathrm{iCa}^{4}$} & \multicolumn{2}{|c|}{ Assay day $\mathrm{tCa}^{3}$} \\
\hline \multicolumn{6}{|c|}{ E. coli-stimulated } \\
\hline Positive $\%^{5}$ & $71.7 \pm 15.9$ & $95.7 \pm 30.0$ & 0.004 & - & 0.14 \\
\hline $\mathrm{GMFI}^{6}$ & $9.8 \pm 3.6$ & $13.2 \pm 5.2$ & 0.02 & - & 0.48 \\
\hline $\mathrm{GMFI}^{6}$ & $41.3 \pm 18.9$ & $101.0 \pm 27.3$ & 0.001 & $44.8 \pm 18.0$ & 0.02 \\
\hline \multicolumn{6}{|c|}{${ }^{1}$ Data were collected from 29 multiparous Holstein cows between 2 and 5 DIM. } \\
\hline \multicolumn{6}{|c|}{${ }^{2}$ Whole blood ionized Ca measured on the day of neutrophil assessment. } \\
\hline \multicolumn{6}{|c|}{${ }^{3}$ Serum total Ca measured on the day of neutrophil assessment by the reference method. } \\
\hline \multicolumn{6}{|c|}{$\begin{array}{l}{ }^{4} \text { Estimate from the multivariate regression model for the effect of the Ca status index on the neutrophil function outcome accounting for th } \\
\text { effects of season and parity (second lactation vs. third and greater). }\end{array}$} \\
\hline
\end{tabular}

The ability to monitor Ca status at the herd and cow level can be a powerful management tool, enabling farm personnel to regularly monitor efficacy of preventative strategies and identify cows in need of intervention. The VetTest was identified as a potential on-farm tool because of its ease of use and relatively low cost of analysis compared with a diagnostic laboratory. This study demonstrated that accounting for the VetTest mean bias in the serum Ca threshold resulted in sensitivities and specificities for identification of hypocalcemia of greater than $85 \%$. At this time, thresholds for identification of hypomagnesemia and hypophosphatemia based on associations with downstream outcomes are not available. As we learn more about early postpartum mineral metabolism, measurement of these parameters may be a valuable diagnostic tool. The measurement of $\mathrm{Mg}$ and $\mathrm{P}$ by the VetTest were higher than measurements by the reference method, which suggests that a correction factor should be used if this tool were implemented in the field for diagnostic purposes. The variation in mean bias for individual VetTest machines was not assessed in the current study, but is a potential factor that should be accounted for when implementing this test. Users should determine the mean bias of the particular machine being used.

The relationship between whole-blood $\mathrm{iCa}$ and reference method serum tCa differed by sampling time point over the first 5 DIM. The variation in these measurements at DIM 3, 4, and 5 was low and the regression at these time points should be interpreted with caution. This relationship should be considered when identifying hypocalcemia using blood iCa concentrations, considering that thresholds based on negative downstream consequences have been established only using blood tCa concentrations. Typically, iCa thresholds have been extrapolated based on previously established relationships that suggested tCa is composed of $50 \% \mathrm{iCa}$ (Lincoln and Lane, 1990); however, this relationship was demonstrated in clinically healthy cows. Other researchers have identified that this relationship varies in the immediate postpartum period (Ballantine and Herbein, 1991; Joyce et al., 1997) when iCa constitutes a greater proportion of tCa. Despite the varying relationship between $\mathrm{iCa}$ and reference method tCa by day postpartum in the current study, adjusting the iCa threshold resulted in sensitivities and specificities greater than $80 \%$ for diagnosing hypocalcemia according to a reference method tCa categorization.

Using an in vitro whole-blood assay for neutrophil oxidative burst activity, measurements of $\mathrm{Ca}$ status on the day of neutrophil assessment were more highly associated with the outcomes of the assay than minimum iCa or reference method tCa before neutrophil assessment. This is likely a reflection of the importance of influx of $\mathrm{Ca}$ from the extracellular fluid that occurs during activation of neutrophils (Martinez et al., 2014); therefore, the blood Ca concentration on the day of neutrophil assessment has greater influence on the outcome measured in vitro than any lingering effects of low blood Ca right after parturition on neutrophil Ca status. Although neither of the parameters measured in vitro in our study captured the full capacity of the immune response, they provide insight into the ability of the circulating neutrophils to respond to different stimuli (positive percent) and the intensity of the stimulated response (GMFI), which demonstrates 
the functional capacity of those cells in relation to Ca status. Previous researchers have reported that cows with subclinical hypocalcemia have increased risk for uterine disease (Martinez et al., 2012). Those cows were also demonstrated to have reduced neutrophil oxidative burst activity, which is hypothesized to be the causal link between the 2 disorders. The relationship between Ca status and neutrophil function was detected in our study using the reference method tCa as a predictor for 1 measure of neutrophil oxidative burst activity, whereas iCa measured on the day of neutrophil assessment was more consistently associated with neutrophil outcomes. This work warrants further investigation into using $\mathrm{iCa}$ as an indicator of functional outcomes requiring $\mathrm{Ca}$ with the potential for more sensitive blood Ca thresholds compared with those established based on tCa. Further work should be done to measure associations between these indicators of Ca status and health and production outcomes in epidemiological data sets.

\section{ACKNOWLEDGMENTS}

The authors gratefully acknowledge the staff at the Cornell University dairy research farms (Cornell University and Dairy-8) and Gladys Birdsall (Cornell University) for care and management of the cows included in the study. We also thank Susanne Pelton for her support in laboratory work and Paula Ospina (Quality Milk Production Services, Cornell University) and Rafael Neves (Cornell University) for advice regarding statistical analyses of these data. The authors thank Phibro Animal Health, Corp. (Quincy, IL) and IDEXX Laboratories Inc. (Westbrook, ME) for partial financial support of this project.

\section{REFERENCES}

Ballantine, H. T., and J. H. Herbein. 1991. Potentiometric determination of ionized and total calcium in blood plasma of Holstein and Jersey cows. J. Dairy Sci. 74:446-449.

Boink, A. B. T. J., B. M. Buckley, T. F. Christiansen, A. K. Covington, A. H. J. Maas, O. Muller-Plathe, C. Sachs, and O. SiggardAndersen. 1991. IFCC recommendation on sampling, transport and storage for the determination of the concentration of ionized calcium in whole blood, plasma and serum. J. Automat. Chem. 13:235-239.

Caixeta, L. S., P. A. Ospina, M. B. Capel, and D. V. Nydam. 2015. The association of subclinical hypocalcemia, negative energy balance and disease with bodyweight change during the first 30 days post-partum in dairy cows milked with automatic milking systems. Vet. J. 204:150-156.

Chamberlin, W. G., J. R. Middleton, J. N. Spain, G. C. Johnson, M. R. Ellersieck, and P. Pithua. 2013. Subclinical hypocalcemia, plasma biochemical parameters, lipid metabolism, postpartum disease, and fertility in postparturient dairy cows. J. Dairy Sci. 96:7001-7013.

Chapinal, N., M. Carson, T. F. Duffield, M. Capel, S. Godden, M. Overton, J. E. Santos, and S. J. LeBlanc. 2011. The association of serum metabolites with clinical disease during the transition period. J. Dairy Sci. 94:4897-4903.

Chapinal, N., M. E. Carson, S. J. LeBlanc, K. E. Leslie, S. Godden, M. Capel, J. E. Santos, M. W. Overton, and T. F. Duffield. 2012. The association of serum metabolites in the transition period with milk production and early-lactation reproductive performance. J. Dairy Sci. 95:1301-1309.

Hammon, D. S., I. M. Evjen, T. R. Dhiman, J. P. Goff, and J. L. Walters. 2006. Neutrophil function and energy status in Holstein cows with uterine health disorders. Vet. Immunol. Immunopathol. 113:21-29.

Joyce, P. W., W. K. Sanchez, and J. P. Goff. 1997. Effect of anionic salts in prepartum diets based on alfalfa. J. Dairy Sci. 80:28662875 .

Kimura, K., J. P. Goff, M. E. Kehrli Jr., and T. Reinhardt. 2002. Decreased neutrophil function as a cause of retained placenta in dairy cattle. J. Dairy Sci. 85:544-550.

Kimura, K., T. A. Reinhardt, and J. P. Goff. 2006. Parturition and hypocalcemia blunts calcium signals in immune cells of dairy cattle. J. Dairy Sci. 89:2588-2595.

Lincoln, S. D., and V. M. Lane. 1990. Serum ionized calcium concentration in clinically normal dairy cattle, and changes associated with calcium abnormalities. J. Am. Vet. Med. Assoc. 197:14711474.

Martinez, N., C. A. Risco, F. S. Lima, R. S. Bisinotto, L. F. Greco, E. S. Ribeiro, F. Maunsell, K. Galvao, and J. E. Santos. 2012. Evaluation of peripartal calcium status, energetic profile, and neutrophil function in dairy cows at low or high risk of developing uterine disease. J. Dairy Sci. 95:7158-7172.

Martinez, N., L. D. R. Sinedino, R. S. Bisinotto, E. S. Ribeiro, G C. Gomes, F. S. Lima, L. F. Greco, C. A. Risco, K. N. Galvao, D. Taylor-Rodriguez, J. P. Driver, W. W. Thatcher, and J. E. R. Santos. 2014. Effect of induced subclinical hypocalcemia on physiological responses and neutrophil function in dairy cows. J. Dairy Sci. 97:874-887.

Ramberg, C. F., Jr., G. P. Mayer, D. S. Kronfeld, J. M. Phang, and M. Berman. 1970. Calcium kinetics in cows during late pregnancy parturition and early lactation. Am. J. Physiol. 219:1166-1177.

Ramos-Nieves, J. M., B. J. Thering, M. R. Waldron, P. W. Jardon, and T. R. Overton. 2009. Effects of anion supplementation to lowpotassium prepartum diets on macromineral status and performance of periparturient dairy cows. J. Dairy Sci. 92:5677-5691.

Reinhardt, T. A., J. D. Lippolis, B. J. McCluskey, J. P. Goff, and R. L. Horst. 2011. Prevalence of subclinical hypocalcemia in dairy herds. Vet. J. 188:122-124.

Roberts, T., N. Chapinal, S. J. Leblanc, D. F. Kelton, J. Dubuc, and T. F. Duffield. 2012. Metabolic parameters in transition cows as indicators for early-lactation culling risk. J. Dairy Sci. 95:30573063.

Rosol, T. J., D. J. Chew, L. A. Nagode, and C. C. Capen. 1995. Pathophysiology of calcium metabolism. Vet. Clin. Pathol. 24:49-63.

Seifi, H. A., M. Mohri, A. Ehsani, E. Hosseini, and M. Chamsaz. 2005. Interpretation of bovine serum total calcium: effects of adjustment for albumin and total protein. Comp. Clin. Pathol. 14:155-159.

Yasui, T., M. M. McCarthy, C. M. Ryan, R. O. Gilbert, M. J. Felippe, G. D. Mechor, and T. R. Overton. 2016. Effects of monensin and starch level in early lactation diets on indices of immune function in dairy cows. J. Dairy Sci. 99:1351-1363. 